\title{
Hyperadrenergic syndrome in severe tetanus: extreme rise in catecholamines responsive to labetalol
}

\author{
G M DOMENIGHETTI, G SAVARY, H STRICKER
}

\begin{abstract}
The hyperadrenergic syndrome that occurs in tetanus is characterised by hypertension, tachycardia, and increased systemic arteriolar resistance. A 74 year old man with tetanus was found to have very high catecholamine concentrations-as high as those in phaeochromocytoma-and the fluctuations in blood pressure and heart rate were measured to see whether they paralleled changes in the catecholamine values. A labetalol infusion of $0.25-1 \mathrm{mg} / \mathrm{min}$ gradually stabilised the cardiovascular disturbances and the patient recovered.
\end{abstract}

\section{Introduction}

Experimental work suggests that tetanospasmin is taken up first by the peripheral endings of motor neurons and then travels along sensory and autonomic nerve fibres. This explains why sympathetic overactivity usually appears a few days after the onset of muscle spasms. This hyperadrenergic syndrome, the blood pressure and heart rate that occur in tetanus are associated with parallel changes in the concentrations of plasma catecholamines.

\section{Case report}

A 74 year old man with no relevant medical history developed severe tetanus. Five days later his blood pressure rose to very high levels with frequent fluctuations between 240 and $120 \mathrm{~mm} \mathrm{Hg}$ systolic and 140 and $70 \mathrm{~mm} \mathrm{Hg}$ diastolic (see figure); his heart rate was also unstable and generally followed the variations in blood pressure. At that time the patient was paralysed and sedated; he was not hypoxaemic and no biological changes were found.

During a hypertensive phase a Swan-Ganz $7 \mathrm{~F}$ thermodilution catheter was introduced: haemodynamic measurements showed a fall in preload and cardiac index with highly increased systemic vascular resistance (mean right atrial pressure $2 \mathrm{~mm} \mathrm{Hg}$; pulmonary capillary wedge pressure $4 \mathrm{~mm} \mathrm{Hg}$; cardiac index $2.311 / \mathrm{min} / \mathrm{m}^{2}$ (normal $\left.2 \cdot 8-4 \cdot 21 / \mathrm{min} / \mathrm{m}^{2}\right)^{4}$; systemic arteriolar resistance 2884 dynes $\mathrm{s} / \mathrm{cm}^{5}$ (normal $770-1500$ dynes $\left.\mathrm{s} / \mathrm{cm}^{5}\right)^{4}$ ).

Plasma catecholamine concentrations were measured during a hypertensive crisis and during the next normotensive phase by the

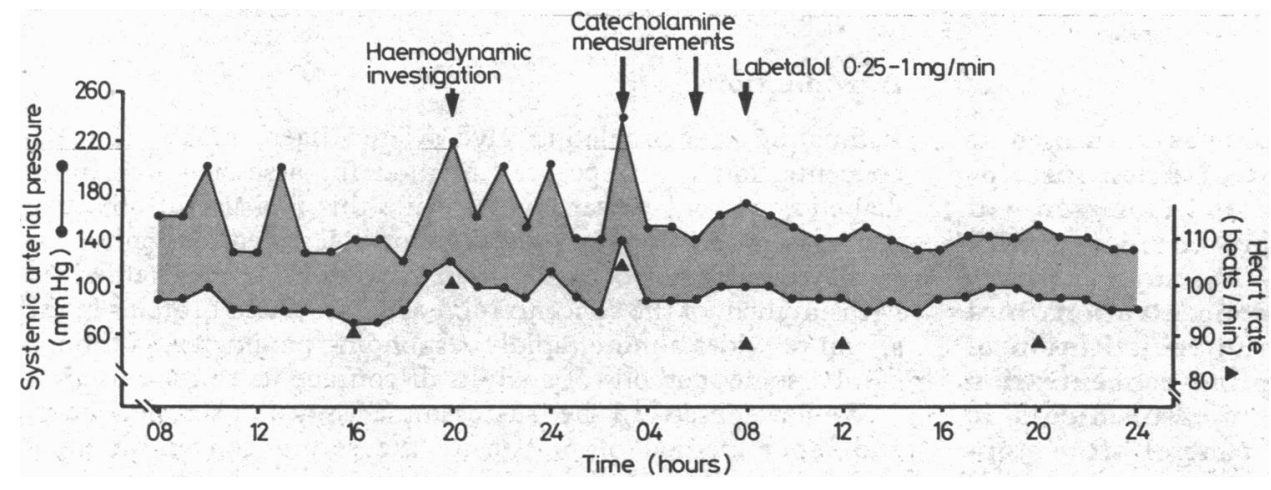

Systemic arterial pressure and heart rate variations before and during labetalol infusion.

which is implicated in most fatal cardiovascular disturbances, is characterised by extreme hypertension, tachycardia, and a rise in systemic arteriolar resistance. In paralysed and sedated patients it suggests an increase in both $\alpha$ and $\beta$ adrenergic activity.

Several workers have reported the presence of raised catecholamine concentrations in patients with tetanus, ${ }^{1-3}$ but the reported values have never been as high as those in phaeochromocytoma. No one has yet shown whether fluctuations in

Intensive Care Unit, District Hospital, Locarno, Switzerland

G M DOMENIGHETTI, MD, consultant physician in intensive care G SAVARY, MD, senior assistant

H STRICKER, MD, senior assistant

Correspondence to: Dr G Domenighetti. radioenzymatic method of Zürcher and Da Prada. During extreme hypertension $(240 / 140 \mathrm{~mm} \mathrm{Hg})$ the plasma concentration of noradrenaline was $14 \cdot 1 \mathrm{nmol} / 1(2380 \mathrm{pg} / \mathrm{ml}$ ) (normal 1.2-2.9 nmol/1 $(200-500 \mathrm{pg} / \mathrm{ml})$ ) and of adrenaline $2 \cdot 3 \mathrm{nmol} / 1(429 \mathrm{pg} / \mathrm{ml}$ ) (normal $0 \cdot 11-0.44 \mathrm{nmol} / 1(20-80 \mathrm{pg} / \mathrm{ml}))$; during the normotensive phase these concentrations were $0.069 \mathrm{nmol} / 1(12.7 \mathrm{pg} / \mathrm{ml})$ and $1.2 \mathrm{nmol} / \mathrm{l}(206 \mathrm{pg} /$ $\mathrm{ml}$ ) respectively. Twenty four hour excretion of urinary catecholamines and their derivatives were determined three times in the convalescent phase to rule out phaeochromocytoma. The mean values were: noradrenaline $124 \mathrm{nmol} / 24 \mathrm{~h}(21 \mu \mathrm{g} / 24 \mathrm{~h}$ ) (normal $89-472 \mathrm{nmol} / 24 \mathrm{~h}(15-80 \mu \mathrm{g} / 24 \mathrm{~h}))$; adrenaline $44 \mathrm{nmol} / 24 \mathrm{~h}(8 \mu \mathrm{g} /$ $24 \mathrm{~h}$ ) (normal $27-55 \mathrm{nmol} / 24 \mathrm{~h}(5-10 \mu \mathrm{g} / 24 \mathrm{~h})$ ); vanillylmandelic acid $23 \mu \mathrm{mol} / 24 \mathrm{~h}(3.9 \mathrm{mg} / 24 \mathrm{~h})$ (normal $<36 \mathrm{nmol} / 24 \mathrm{~h}(<6 \mathrm{mg}$ ) $24 \mathrm{~h})$ ).

Labetalol was then started in titrated infusions of $0.25-1 \mathrm{mg} / \mathrm{min}$ (see figure). This gradually stabilised the cardiovascular disturbances. The patient recovered uneventfully and was discharged 55 days after admission.

\section{Discussion}

The prompt treatment of the syndrome of sympathetic overactivity in severe tetanus should take into account the 
haemodynamic changes, which seem to be similar to those found in phaeochromocytoma. ${ }^{5}$

The haemodynamic measurements in this patient suggested highly increased adrenergic activity: hypertension associated with decreased preload and cardiac index and severely increased systemic vascular resistance. This particular pattern was confirmed by the presence of very high plasma catecholamine concentrations, similar to those found in phaeochromocytoma. In this condition the introduction of a $\beta$ blocker with its inhibitory effects on cardiac $\beta$ receptors might be detrimental, reducing the cardiac index to values found in shock. The antihypertensive drug labetalol appears to be particularly effective in controlling sympathetic overactivity in tetanus ${ }^{6}$; with its combined $\alpha$ and $\beta$ blocking actions the risks of an unbalanced $\alpha$ stimulation are minimised.

Finally, our results show that in severe tetanus the changes in heart rate and blood pressure seem to parallel changes in catecholamine concentrations, at least during the early phase of the disease.
We thank Professor Fritz Bühler, University Hospital, Basle, for determining plasma catecholamine concentrations.

\section{References}

${ }^{1}$ Keilty SR, Gray RC, Dundee JW, et al. Catecholamine levels in severe tetanus. Lancet $1968 ; \mathrm{ii}: 195$.

${ }^{2}$ Kerr JH, Corbett JL, Prys-Roberts C, et al. Involvement of the sympathetic nervous system in tetanus. Studies on 82 cases. Lancet 1968;ii 236-41.

${ }^{3}$ Kanarek DJ, Kaufmann B, Zwi S. Severe sympathetic hyperactivity associated with tetanus. Arch Intern Med 1973;132:602-4.

${ }^{4}$ Grossman W. Cardiac catheterization and angiography. Philadelphia: Lea and Febiger, 1974.

${ }^{5}$ Pécoud A, Francioli P, Pradervand D, et al. Haemodynamics in phaeochromocytoma. A report of 2 cases. Intensive Care Med 1979;5:143-6.

${ }^{6}$ Dundee JW, Morrow WFK. Labetalol in severe tetanus. Br Med $\mathrm{f}$ 1979;i:1121-2.

(Accepted 14 February 1984)

\title{
Serum fructosamine concentrations in patients with type II (non-insulin-dependent) diabetes mellitus during changes in management
}

\author{
JOHN R BAKER, ROGER N JOHNSON, DAVID J SCOTT
}

\begin{abstract}
The serum fructosamine concentration was examined as a new means to monitor metabolic control in non-insulindependent diabetes during changes in management. Weekly fructosamine estimations were compared with glycosylated haemoglobin $\left(\mathbf{H b} \mathbf{A}_{\mathrm{Ic}}\right), 24$ hour urinary glucose, and fasting plasma glucose concentrations in a 17 week study entailing withdrawal and reinstitution of oral treatment. The serum fructosamine concentration was more sensitive than the other measurements in detecting a deterioration in diabetic control after stopping oral hypoglycaemic drugs. The response to reinstitution of treatment was not significant in the first three weeks $(p=0 \cdot 266)$, despite a highly significant reduction in fasting plasma glucose $(p=0.001)$ and 24 hour urinary glucose concentrations $(p=0.012)$.

Compared with $\mathbf{H b A}_{\mathrm{lc}}$, concentrations of fructosamine appeared more useful in monitoring short term (three to six weeks) changes after alterations in management of diabetes. Additional advantages were lower cost and technical simplicity of measurement.
\end{abstract}

\footnotetext{
Department of Clinical Biochemistry, Green Lane Hospital, Auckland, New Zealand

JOHN R BAKER, MB, chemical pathologist

ROGER N JOHNSON, PHD, scientific officer

Academic Medical Unit, Middlemore Hospital, Otahuhu, Auckland, New Zealand

DAVID J SCOTT, FRCP, physician
}

Correspondence to: Dr John R Baker, Department of Clinical Biochemistry, Green Lane Hospital, Private Bag, Auckland, New Zealand.

\section{Introduction}

Estimating the circulating glycosylated haemoglobin $\left(\mathrm{HbA}_{\mathrm{lc}}\right)$ concentration is an accepted method for assessing long term diabetic control. ${ }^{1}$ Nevertheless, while this is a useful objective test to assess stable glycaemia, it is not well suited to monitor the rapid changes that occur with an alteration in management. ${ }^{23}$ Measurement of the concentration of glycosylated proteins in the serum provides a more rapidly responding parameter, ${ }^{4}$ although cumbersome methods of analysis discourage its routine use. ${ }^{5}$

We have described the fructosamine assay as a simple, cheap, and rapid method of measuring the serum concentration of glycosylproteins. ${ }^{6}$ The present study was undertaken to determine the clinical usefulness of fructosamine estimations in monitoring alterations in management in a group of patients with non-insulin-dependent (type II) diabetes mellitus.

\section{Patients and methods}

We studied five men and two women with mild non-insulindependent diabetes mellitus in whom random blood glucose measurements at the past three clinic visits had yielded values less than $10 \mathrm{mmol} / 1(180 \mathrm{mg} / 100 \mathrm{ml})$. All were white, and none showed clinical evidence of organic diabetic complications. The table summarises their clinical details. All patients had normal liver and renal function and normal haematological profiles. Participants gave informed consent at the outset, and the study was approved by the human ethics committee of Auckland Hospital.

Reference intervals for fructosamine, fasting plasma glucose, and $\mathrm{HbA}_{1 \mathrm{c}}$ values were determined in 30 healthy non-diabetic volunteers from the hospital laboratory aged $18-55$ years (median 28). Diabetes was rigorously excluded from this reference population using the plasma insulin and $C$ peptide responses to intravenous glucagon. ${ }^{8}$

Patients were seen weekly for 17 weeks. They took their usual medication and diet during the first five weeks and from week 11 to the completion of the study. From weeks 5 to 11 oral hypoglycaemic treatment was withdrawn. Fasting blood specimens and a 24 hour urine collection were obtained at weekly intervals. 